\title{
Antioxidant Composition of a Selection of Italian Red Wines and Their Corresponding Free-Radical Scavenging Ability
}

\author{
Claudio Cassino, ${ }^{1}$ Valentina Gianotti, ${ }^{1}$ Federica Bonello, ${ }^{2}$ Christos Tsolakis, ${ }^{1,2}$ \\ Maria Carla Cravero, ${ }^{2}$ and Domenico Osella ${ }^{1}$ \\ ${ }^{1}$ Dipartimento di Scienze e Innovazione Tecnologica, Università degli Studi del Piemonte Orientale, \\ Viale T. Michel 11, 15121 Alessandria, Italy \\ ${ }^{2}$ CREA Consiglio per la Ricerca in Agricoltura e l'Analisi dell'Economia Agraria, Centro di Ricerca per l'Enologia, \\ Via P. Micca 35, 14100 Asti, Italy \\ Correspondence should be addressed to Claudio Cassino; claudio.cassino@uniupo.it
}

Received 15 December 2015; Revised 17 March 2016; Accepted 6 April 2016

Academic Editor: Philippe Jeandet

Copyright ( 12016 Claudio Cassino et al. This is an open access article distributed under the Creative Commons Attribution License, which permits unrestricted use, distribution, and reproduction in any medium, provided the original work is properly cited.

\begin{abstract}
This study correlates the antioxidant composition profiles and the overall antioxidant capacities of 36 Italian red wine samples. The samples were fully characterized by chromatographic and spectrophotometric techniques. The overall antioxidant capacity was determined by titrating a solution of the semistable free radical DPPH (1,1-diphenyl-2-picrylhydrazyl) with each wine sample followed by Electron Paramagnetic Resonance (EPR) spectroscopy and then measuring the resulting decrease in DPPH-signal. The antioxidant activities of the samples were expressed as (+)-catechin equivalents and related to their antioxidant composition profiles. Samples with a high polyphenol content showed a high DPPH scavenging ability as well. Seven well-defined groups, mainly constituted by wines coming from the same cultivar, were evidenced by PCA analysis. Alcohol content and $\mathrm{pH}$ did not influence the wine DPPH scavenging ability. The most important variables contributing to the wines' antioxidant power are total flavonoid, total phenol, and proanthocyanidin indices together with fertaric acid, trans-caftaric acid, trans-coutaric acid, and both quercetin glucoside and quercetin glucuronide. EPR is demonstrated to be faster than the other analytical methods (spectrophotometric and chromatographic analyses) to determine the wine overall antioxidant activity.
\end{abstract}

\section{Introduction}

Wine has been part of human culture for thousands of years and is an important component of the traditional Mediterranean diet. Although the excessive use of alcohol can lead to serious health problems, a number of studies suggest that moderate consumption of wine (especially red) may provide health benefits. According to the Dietary Guidelines for Americans [1], moderate alcohol consumption is defined as having up to 1 drink (a glass, $150 \mathrm{~mL} 12 \%$ alcohol wine) per day for women and up to 2 drinks (two glasses, $300 \mathrm{~mL} \mathrm{12 \%}$ alcohol wine) per day for men. Positive effects derive from the strong antioxidant properties of polyphenolic compounds [2]. Red wines generally contain higher levels of polyphenolics than white ones. These compounds not only contribute to the colour, flavour, astringency, and bitterness of a wine but also serve to fight free radicals in the body that cause disease and ageing. Epidemiological studies pointed out that the consumption of red wine has been shown to increase the body's antioxidant capacity and is associated with a lower risk of mortality from cardiovascular diseases [3, 4].

There are two major classes of wine phenolics: nonflavonoids and flavonoids. The relative amount and distribution of these compounds depend on a variety of factors such as grape variety, vineyard location, climate, soil type, cultivation practices, harvesting time, production process, and wine ageing [5-8].

The class of flavonoids includes several molecules characterized by their functionalities on the benzene rings. The most important flavonoids in wine are anthocyanidins, flavanols (also known as catechins or flavan-3-ols), and flavonols (including quercetin and myricetin). Proanthocyanidins, 
dimers, or oligomers of catechin and epicatechin and their gallic acid esters are also classified as flavonoids. Red wines contain wide-ranging concentrations of proanthocyanidins.

The term nonflavonoid usually includes different classes of substituted phenols. These different congeners can be grouped as benzoic-based compounds (i.e., vanillic and gallic acids), benzaldehydes (vanillin and syringaldehyde), cinnamic acids ( $p$-coumaric, ferulic, and caffeic acids), and cinnamaldehydes (coniferyl aldehyde and sinapylaldehyde). These classes can be further subdivided by the number and type of substituents present.

Ascorbic acid and sulfur dioxide, $\mathrm{SO}_{2}$, also contribute to the antioxidant power of wine [9]. These compounds are naturally present in wine in very low amounts but are often added as preservatives during the winemaking process.

$\mathrm{SO}_{2}$ exerts its antioxidant effect by destroying the polyphenol oxidase (PPO) enzyme responsible for phenol oxidation [10], but it was observed [11] that the content of polyphenols and flavonoids was similar in organic and conventional red wines as well as their antioxidant activity.

A wide variety of compounds contributes to the antioxidant power of wine, making it difficult to determine the relative contribution of each antioxidant species. Profound interactions between the compounds may take place, and the total antioxidant power of a wine may not correspond to the sum of the antioxidant capacities of each single molecule [12].

Recently, studies performed on grape skins, seeds [1315], and wines [16-18] have appeared in the literature. These studies correlate the overall antioxidant power of the different wine samples (via EPR determination) with the total amount of polyphenols, but there is little information about the interactions within the single class of compounds.

To date, the antioxidant parameters of most wines produced in Italy have not been fully determined. There are only a few works regarding Italian wines [19], although one thorough study on wines coming from different zones of Campania (Italy) has been published [20]. This lack of available information is unfortunate, since, consequently, wine producers do not always take advantage of the commercial value associated with the antioxidant activity of wine, by making related claims in advertising.

From a statistical point of view, univariate methods have usually been applied for determining relationships between total or individual phenols with the antioxidant properties of red wines $[21,22]$. This one-dimensional approach, however, fails to determine simultaneous correlations. To overcome this problem, the use of chemometric methods, which are intrinsically multivariate in nature, has been recognized as a valuable tool in wine science, for example, to assure wines' authenticity and quality [23], to classify their geographical origin $[24,25]$, and to evaluate their sensory properties [26].

In the present work, all the possible sources of antioxidant activity were sought to obtain information about their role in the overall antioxidant power.

Usually, the antioxidant activity of a molecule is measured by evaluating its ability to scavenge radicals produced in vitro. In this study, the moderately stable 1,1-diphenyl-2-picrylhydrazyl (DPPH) organic radical was employed as a standard reagent for the measurement of the antioxidant capacity of wines. Even though this radical is not present in biological systems, it is often employed, since it is reasonably stable in water and in the presence of air [27]. Electron Paramagnetic Resonance (EPR) was the method of choice for providing this parameter [28].

The analyses were performed on red wines coming from different Italian regions, different cultivars, different winemaking techniques, and different ageing times, in order to have widely heterogeneous samples able to cover all possible factors influencing the antioxidant activity of grapes and wines [29]. All the data collected were analysed by the multivariate statistical method of the Principal Component Analysis (PCA) in order to find the possible correlation between the total antioxidant activity measured and the concentration of each class of antioxidant analysed.

\section{Materials and Methods}

2.1. Reagents. Ultrapure water, calcium oxide, phosphoric acid $85 \%$, hydrogen peroxide, mixed indicator ( $\mathrm{pH} 5.1$ ), FolinCiocalteu reagent (phosphomolybdic acid and phosphowolframic acid mixture), absolute ethanol, hydrochloric acid $37 \%$, sodium hydroxide solution $1 \mathrm{M}$, methanol (HPLC gradient grade), sulfuric acid $1 \mathrm{~N}$, sodium carbonate, iron sulfate heptahydrate $\left(\mathrm{FeSO}_{4} \cdot 7 \mathrm{H}_{2} \mathrm{O}\right)$, 1,1-diphenyl-2-picrylhydrazyl (DPPH), quercetin dehydrate, and $p$-coumaric acid were all purchased from Sigma-Aldrich (Milan, Italy) and used as received. Caffeic acid and ferulic acid were purchased from Extrasynthese (Lyon, France).

2.2. Samples. Thirty-six wines (Table 1) from different Italian regions were analysed. They were produced in experimental cellars, where the different steps of the winemaking process were controlled and traceable. The winemaking procedure used also allowed for limited and controlled addition of nonnatural antioxidant products. The information about cultivars is shown in Table 1.

All the chemical and physical determinations were performed in triplicate.

Each sample was coded as indicated in Table 1. Numbers added at the end of each code identify repetitions of analysis.

2.3. Instrumentation. Determination of anthocyanins, flavonols, proanthocyanidins, and total phenols was carried out using a Jasco V-550 UV-VIS spectrophotometer (Tokyo, Japan).

The qualitative-quantitative analysis of HCTAs and flavonols was performed with HP 1090 Hewlett-Packard (Palo Alto, California, USA) HPLC liquid chromatograph equipped with a Diode Array Detector (DAD).

For EPR determination, a JEOL FA-200 X band EPR spectrometer (JEOL Ltd., Tokyo, Japan) with a flat cell (JEOL ES-LC11) was used.

2.4. Analytical Methods. The concentrations of alcohol $(\mathrm{OH})$ and ascorbic acid (AA), $\mathrm{pH}$, and free $\mathrm{SO}_{2}$ content were determined according to the standard procedures reported in the EEC 2676/90. 
TABLE 1: An overview of the wine samples investigated.

\begin{tabular}{|c|c|c|c|c|c|}
\hline Cultivar & Code & PCA code & Region & Vintage & Winemaking technique \\
\hline Albarossa & $\mathrm{A} 10 \mathrm{~T}$ & $1 \mathrm{~T}(1,2,3)$ & Piedmont & 2010 & Traditional \\
\hline Albarossa & $\mathrm{A} 10 \mathrm{C}$ & $2 \mathrm{C}(1,2,3)$ & Piedmont & 2010 & With cryomaceration \\
\hline Albarossa & A10MC & $3 \mathrm{MC}(1,2,3)$ & Piedmont & 2010 & With hot prefermentative maceration \\
\hline Cornarea & $\mathrm{C} 10 \mathrm{~T}$ & $4 \mathrm{~T}(1,2,3)$ & Piedmont & 2010 & Traditional \\
\hline Cornarea & $\mathrm{C} 10 \mathrm{C}$ & $5 \mathrm{C}(1,2,3)$ & Piedmont & 2010 & With cryomaceration \\
\hline Cornarea & $\mathrm{C} 10 \mathrm{MC}$ & $6 \mathrm{MC}(1,2,3)$ & Piedmont & 2010 & With hot prefermentative maceration \\
\hline Refosco & R10Ve & $7 \mathrm{Ve}(1,2,3)$ & Veneto & 2010 & Traditional \\
\hline Refosco & $\mathrm{R} 10 \mathrm{Ma}$ & $8 \mathrm{Ma}(1,2,3)$ & The Marches & 2010 & Traditional \\
\hline Refosco & R09Ve & $9 \mathrm{Ve}(1,2,3)$ & Veneto & 2009 & Traditional \\
\hline Refosco & R09Ma & $10 \mathrm{Ma}(1,2,3)$ & The Marches & 2009 & Traditional \\
\hline Nero d'Avola & NA10Ve & $11 \mathrm{Ve}(1,2,3)$ & Veneto & 2010 & Traditional \\
\hline Nero d'Avola & NA10Ma & $12 \mathrm{Ma}(1,2,3)$ & The Marches & 2010 & Traditional \\
\hline Nero d'Avola & NA09Ve & $13 \mathrm{Ve}(1,2,3)$ & Veneto & 2009 & Traditional \\
\hline Nero d'Avola & NA09Ma & $14 \mathrm{Ma}(1,2,3)$ & The Marches & 2009 & Traditional \\
\hline Primitivo & P08 & 15_(1,2,3) & Apulia & 2008 & Traditional with ageing in barriques \\
\hline Primitivo & P09 & 16_(1,2,3) & Apulia & 2009 & Traditional with ageing in barriques \\
\hline Primitivo & $\mathrm{P} 10$ & 17_(1,2,3) & Apulia & 2010 & Traditional with ageing in barriques \\
\hline Cabernet s. & CaT101 & 18_(1,2,3) & Piedmont & 2001 & Vineyard with canopy management \\
\hline Cabernet s. & CaT201 & 19_(1,2,3) & Piedmont & 2001 & Grapes with canopy management \\
\hline Cabernet s. & СaT301 & $20 \_(1,2,3)$ & Piedmont & 2001 & Grapes with canopy management \\
\hline Cabernet s. & CaT401 & $21 \_(1,2,3)$ & Piedmont & 2001 & Grapes with canopy management \\
\hline Cabernet s. & CaT501 & $22 \_(1,2,3)$ & Piedmont & 2001 & Grapes with canopy management \\
\hline Cabernet s. & CaT601 & $23 \_(1,2,3)$ & Piedmont & 2001 & Grapes with canopy management \\
\hline Cabernet s. & CaT701 & $24 \_(1,2,3)$ & Piedmont & 2001 & Grapes with canopy management \\
\hline Cabernet s. & CaT801 & $25 \_(1,2,3)$ & Piedmont & 2001 & Grapes with canopy management \\
\hline Cabernet s. & CaT901 & $26 \_(1,2,3)$ & Piedmont & 2001 & Grapes with canopy management \\
\hline Uvalino & U06 & $27 \_(1,2,3)$ & Piedmont & 2006 & Traditional \\
\hline Uvalino & U04 & $28 \_(1,2,3)$ & Piedmont & 2004 & Traditional \\
\hline Primitivo & $\mathrm{P} 10 \mathrm{M}$ & $29 \mathrm{M}(1,2,3)$ & Apulia & 2010 & Traditional with ageing in barriques \\
\hline Primitivo & P10SM & $30 \mathrm{SM}(1,2,3)$ & Apulia & 2010 & Traditional with ageing in barriques \\
\hline Primitivo & P11M & $31 \mathrm{M}(1,2,3)$ & Apulia & 2011 & Traditional with ageing in barriques \\
\hline Primitivo & P11SM & $32 \operatorname{SM}(1,2,3)$ & Apulia & 2011 & Traditional with ageing in barriques \\
\hline Gaglioppo & G09nosd & 33_(1,2,3) & Calabria & 2009 & Without seeds in steel \\
\hline Gaglioppo & G09sd & 34_(1,2,3) & Calabria & 2009 & With seeds in steel \\
\hline Gaglioppo & G09nosdbq & $35 \_(1,2,3)$ & Calabria & 2009 & Without seeds in barriques \\
\hline Gaglioppo & G09sdbq & $36 \_(1,2,3)$ & Calabria & 2009 & With seeds in barriques \\
\hline
\end{tabular}

The determination of total phenol (TP), total anthocyanin (TA), proanthocyanidin (PA), and total flavonoid (TF) indices was performed according to the methods described by Di Stefano et al. [30].

For hydroxycinnamoyl-tartaric acids (HCTAs) and flavonol determinations, chromatographic methods previously reported by Di Stefano and Cravero [31] were used.

HPLC separations were performed using a C18 column ODS Hypersil RP-18 $(200 \times 2.1 \mathrm{~mm}, 5 \mathrm{~mm})$ (Thermo Scientific) and the mobile phase gradient reported in Table 2. Solvent $\mathrm{A}$ is $1 * 10^{-3} \mathrm{M}$ phosphoric acid and solvent $\mathrm{B}$ is methanol. The flow rate was $0.25 \mathrm{~mL} \mathrm{~min}{ }^{-1}$ and the volume injected was $20 \mu \mathrm{L}$.
Flavonols were determined registering the chromatogram at $360 \mathrm{~nm}$ [32]. In particular, quercetin glucoside (Q1), quercetin glucuronide (Q2), and myricetin (MY) were identified and quantified by the response factor method and reported as an equivalent of quercetin dehydrate.

HCTAs were identified and quantified by the chromatograms registered at $320 \mathrm{~nm}$. The amount of HCTAs was reported as $p$-coumaric acid equivalents for cis- (CC) and trans- (TC) p-coumaroyl tartaric acid (cis-, trans-coutaric acid), as caffeic acid equivalents for cis- (CF) and trans(TE) caffeoyl tartaric acids (cis-, trans-caftaric acid), and as ferulic acid equivalents for trans- (TL) feruloyl tartaric acid (trans-fertaric acid), using the response factor method. 
TABLE 2: HPLC mobile phase gradient conditions.

\begin{tabular}{lcc}
\hline Minutes & $\begin{array}{c}\text { Solvent } \mathrm{A} \\
\mathrm{H}_{3} \mathrm{PO}_{4} 0.001 \mathrm{M}\end{array}$ & $\begin{array}{c}\text { Solvent B } \\
\text { Methanol }\end{array}$ \\
\hline $0-5$ & From $95 \%$ to $90 \%$ & From $5 \%$ to $10 \%$ \\
$5-20$ & From $90 \%$ to $70 \%$ & From $10 \%$ to $30 \%$ \\
$20-30$ & From $70 \%$ to $40 \%$ & From $30 \%$ to $60 \%$ \\
$30-40$ & From $40 \%$ to $0 \%$ & From $60 \%$ to $100 \%$ \\
$40-45$ & $0 \%$ & $100 \%$ \\
$45-50$ & From 0 to $95 \%$ & from 100 to $5 \%$ \\
$50-55$ & \multicolumn{2}{c}{ Equilibration time } \\
\hline
\end{tabular}

The concentration of cis-feruloyl tartaric acid was too low to be determined.

2.5. EPR Measurements. For experiments of free-radical scavenging, $990 \mu \mathrm{L}$ of a $250 \mu \mathrm{M}$ DPPH solution in methanol was added to $10 \mu \mathrm{L}$ of each wine sample. The mixture was then transferred to a flat cell for the analysis of the residual DPPH radicals. The measurements were performed 5, 10, and 15 minutes after the addition of DPPH. The signal areas were evaluated by double integrating the recorded EPR signal in the region between 326 and $330 \mathrm{mT}$. EPR spectroscopic analyses were carried out under the following conditions: temperature $25^{\circ} \mathrm{C}$; magnetic field $329 \pm 5 \mathrm{mT}$; field modulation width $0.1 \mathrm{mT}$; field modulation frequency $100 \mathrm{KHz}$; receiver gain 200; time constant $0.03 \mathrm{~s}$; sweep time $30 \mathrm{~s}$; microwave power $4 \mathrm{~mW}$. The percentage ratio of the signal areas of wine and reference samples after 5, 10, and 15 minutes from $\mathrm{DPPH}$ addition was calculated. The reference sample was prepared adding $10 \mu \mathrm{L}$ of a $12 \% \mathrm{v} / \mathrm{v}$ ethanol aqueous solution to $990 \mu \mathrm{L}$ of the $250 \mu \mathrm{M}$ DPPH stock solutions in methanol. $(+)$-Catechin was chosen as the reference antioxidant to express the free-radical scavenging activity measured by EPR. Different amounts of a $400 \mu \mathrm{M}(+)$-catechin solution in methanol were added to $400 \mu \mathrm{L}$ of a $250 \mu \mathrm{M}$ DPPH methanol solution. Methanol was then added to reach the final volume of $500 \mu \mathrm{L}$. The obtained samples were $200 \mu \mathrm{M}$ in DPPH and had a (+)-catechin concentration ranging from 8 to $56 \mu \mathrm{M}$. The percentage ratio of the signal areas of $(+)$-catechin and reference samples after 5, 10, and 15 minutes from DPPH addition was calculated. For (+)-catechin, the reference sample was prepared by adding $100 \mu \mathrm{L}$ of methanol to $400 \mu \mathrm{L}$ of the $250 \mu \mathrm{M}$ DPPH stock solution in methanol. Figure 1 shows the antiradical activity observed for $(+)$-catechin.

The free-radical scavenging activity of the wines under investigation ( $\mathrm{T} 5, \mathrm{~T} 10$, and $\mathrm{T} 15)$ was reported as the equivalent amount of $(+)$-catechin $\left(\mathrm{mg} \mathrm{L}^{-1}\right)$ necessary to identically quench the EPR signal of DPPH after the same contact time.

2.6. Statistical Analysis. PCA is a pattern recognition method representing objects in a new reference system characterized by variables called Principal Components (PCs) well described elsewhere [33]. Briefly, PCs are orthogonal to each other and are computed hierarchically (the information accounted for by successive PCs is decreasing). Each PC has the property of explaining the maximum possible amount of

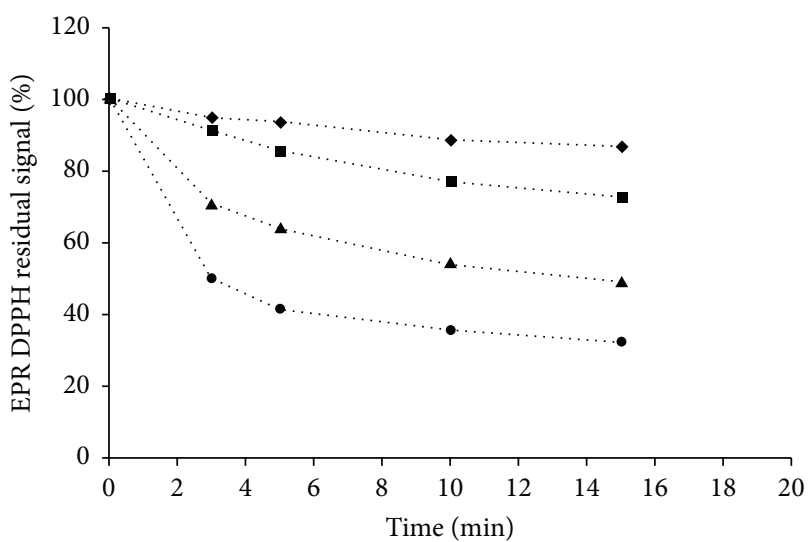

FIGURE 1: Quenching of radical activity by $(+)$-catechin solutions with time. $8 \mu \mathrm{M}$ (diamonds), $24 \mu \mathrm{M}$ (squares), $40 \mu \mathrm{M}$ (up triangles), and $56 \mu \mathrm{M}$ (circles).

variance contained in the original dataset. The PCs, which are expressed as linear combinations of the original variables, are used for an effective representation of the system under investigation with a lower number of variables than in the original case. The coordinates of the samples in the new reference system are called scores, while the coefficients of the linear combination describing each PC, that is, the weights of the original variables on each PC, are called loadings.

Principal Component Analysis and all graphical representations were performed using Statistica 7.1 (Dell Statistica, Tulsa, Oklahoma, USA) and Excel 2013 (Microsoft Corporation, Redmond, Washington, USA).

\section{Results and Discussion}

Thirty-six wines obtained from the 9 cultivars (Table 1) were analysed for the 20 parameters reported in the experimental section. The wines were produced in experimental cellars where the use of chemical additives such as ascorbic acid was avoided, while the $\mathrm{SO}_{2}$ addition was kept as low as possible.

Samples were produced using grapes grown in different areas of Italy (with a variety of soils and climatic characteristics) and from different cultivars. In this way, the set of samples guarantees adequate heterogeneity of the agronomic and viticulture characteristics.

The entire dataset, obtained analysing each wine sample, is available as supplementary material (in Supplementary Material available online at http://dx.doi.org/10.1155/2016/ 4565391). As expected, since the wines chosen for the study are very heterogeneous, the experimental values obtained for antioxidant concentrations are spread over a wide range.

In particular, the total phenol index ranged from 765 to $5745 \mathrm{mg} \mathrm{L}^{-1}$ (the average being $2160 \mathrm{mg} \mathrm{L}^{-1}$ ) [34, 35], the total anthocyanin index from 18 to $687 \mathrm{mg} \mathrm{L}^{-1}$, the total flavonoid index from 810 to $5260 \mathrm{mg} \mathrm{L}^{-1}$, and the proanthocyanidin index from 761 to $6900 \mathrm{mg} \mathrm{L}^{-1}$. The alcohol content ranged between 9.64 and $16.38 \% \mathrm{v} / \mathrm{v}$. It is important to point out that the majority of $\mathrm{SO}_{2}$ comes from the addition of potassium metabisulfite to grapes and wine. The wines studied here were 


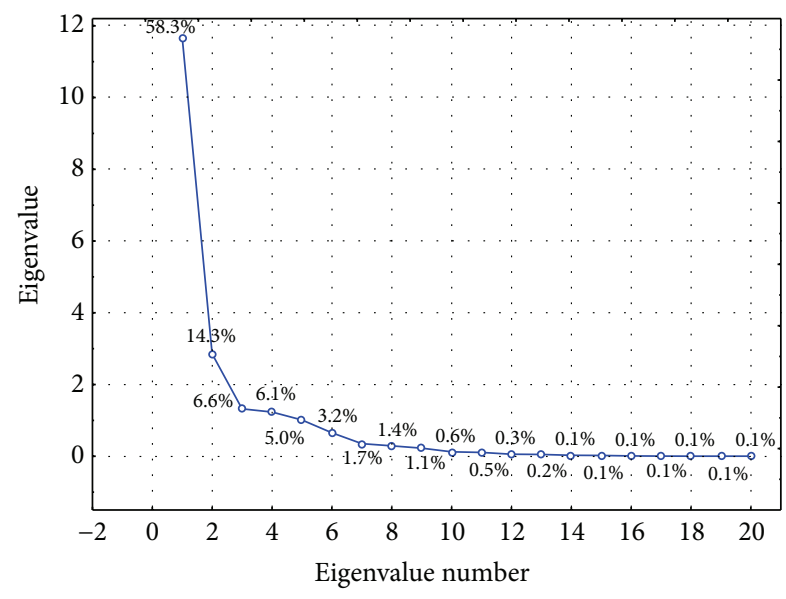

FIGURE 2: Scree plot obtained by performing PCA on the complete dataset.

characterised by very low free $\mathrm{SO}_{2}$ values ranging from 0 to $28 \mathrm{mg} \mathrm{L}^{-1}$. These analytical results confirmed the claims of cellars who added only the minimum $\mathrm{SO}_{2}$ amount required to preserve the wine, even if higher amounts are allowed by the Italian law. The ascorbic acid concentration was below the detection limit for all the samples measured.

HCTAs (caftaric, coutaric, and fertaric acid) and flavonols (quercetin and myricetin) were present in low concentrations, as expected [36]; even if they were originally present at high concentration in grapes, their amount decreased significantly during fermentation and ageing.

The quenching of DPPH signal is a function of both contact time and the amount of antioxidant compounds added. Figure S1, reported as an example, shows the decrease of the DPPH EPR signal with time after the addition of a given amount of wine. The most common standard employed to quantify the overall antioxidant capacity of wine is (+)catechin. Noteworthy, kinetics of free-radical quenching of the wines under investigation and $(+)$-catechin were very similar during the EPR experiment, giving rise to the meaningful T5, T10, and T15 parameters as described in Section 2.5.

Gaglioppo and Cornarea wines showed the highest antioxidant activity, while Nero d'Avola and Cabernet showed the lowest one. For the Cabernet wines (produced in 2001), this fact can be explained by the ageing effect, which leads to a drastic depletion of the polyphenol content. In general, samples with a high polyphenol content showed a high DPPH scavenging ability as well.

The experimental data clearly indicate profound differences among the samples, and finding correlation in the dataset appears to be a complex task especially by the classical univariate approach. Therefore, PCA analysis was performed on the complete dataset in which the variables were autoscaled to eliminate their inhomogeneity. The scree plot in Figure 2 shows that the first PC (PC1) explains about $61 \%$ and the second PC (PC2) about $15 \%$ of the total variance contained in the original dataset. Therefore, the successive PCs can be considered as not statistically significant.

In Figure 3, the score plot obtained for the first two PCs is reported in which the samples of the same cultivar

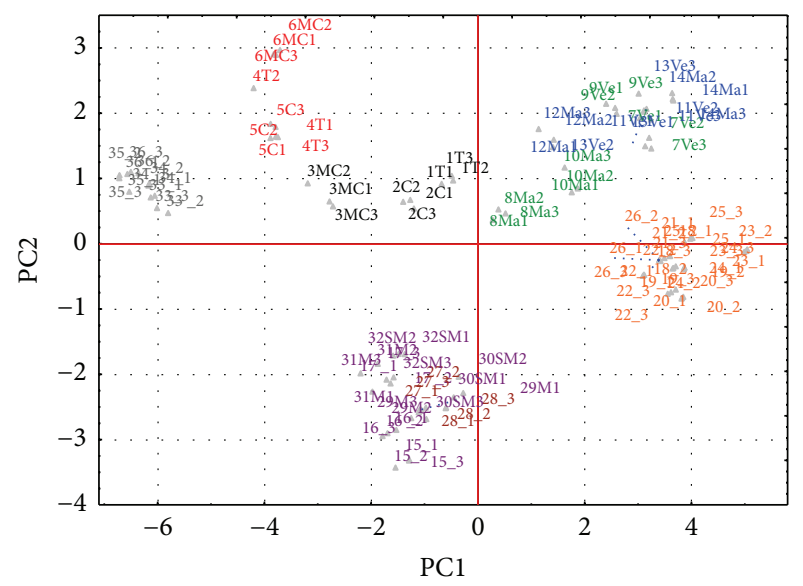

Figure 3: Score plot of PC1 versus PC2.

have the same colour code. The first two PCs allow effective separation of the samples into different classes. Results from three sample replicates proved to be very similar, indicating excellent repeatability for all parameters examined.

In particular, seven well-defined groups can be identified (Figure 3), mainly constituted by wines coming from the same cultivar. The exceptions are Nero d'Avola and Refosco, whose data partially overlapped.

Accurate interpretation of the parameters leading to this grouping of the samples requires the loading plot information reported in the histogram of Figure 4 that represents the weights of the original variables on each PC.

Many of the variables studied show negative weights on PC1. In particular, the variables related to the EPR analyses and the proanthocyanidin, the total flavonoid, and the total phenol indices are located at high negative weights. Moreover, a lower but still significant contribution is also present for quercetin glucoside, quercetin glucuronide, and transcaftaric acid, which have a lower negative weight. $\mathrm{pH}$ is the only variable placed at a positive weight on $\mathrm{PC1}$, but its value is not so high.

Within the first PC, the EPR values and the content of polyphenols have the same sign, indicating that there is a strong correlation between them and that they account for the same information. For those reasons, the meaning of "antioxidant power" can be assigned to the macrovariables PC1. This macrovariable distinguishes very well between Gaglioppo and Cornarea (which have a high antioxidant capacity) from Cabernet sauvignon, Refosco, and Nero d'Avola. Figure 3 clearly illustrates the antioxidant activity attribute of the cultivars under study, showing their position along the $\mathrm{PC1}$ axis. Antioxidant power increases, in fact, when moving from the right to the left side of the figure. In detail, the samples placed in the negative part of the PC1 are characterized by high values of the variables having negative weight on this $\mathrm{PC}$ and by low values of the ones having positive weight. The opposite is true for the samples placed in the positive part of PC1.

It is important to note that the antioxidant power of the Gaglioppo samples is much stronger than that of all the other 


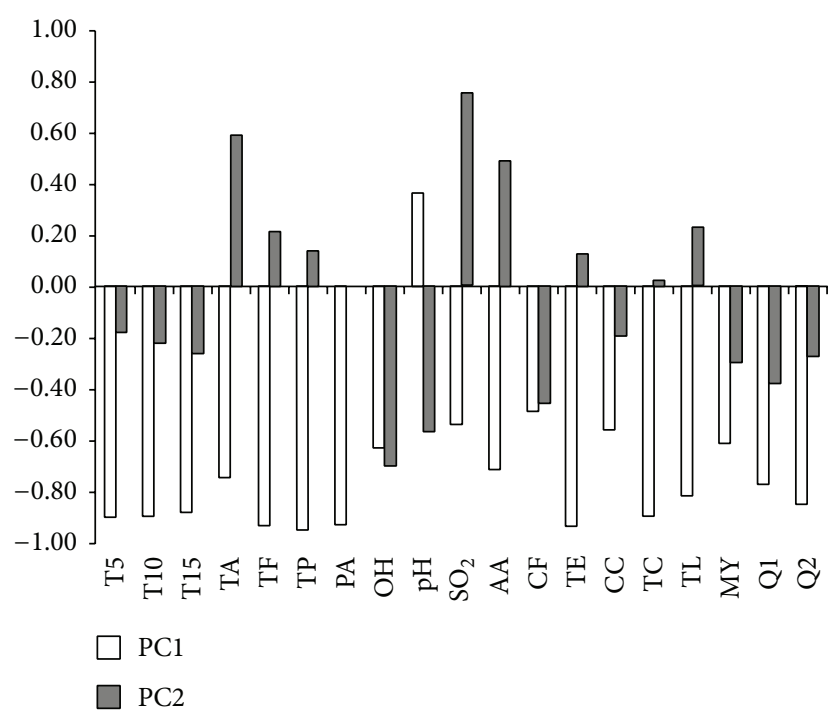

FIgURE 4: Loading plot reporting PC1 versus PC2. The following abbreviations were used: T5, T10, and T15: wine free-radical scavenging activity after 5, 10, and 15 minutes, TA: total anthocyanin index, TF: total flavonoid index, TP: total phenol index, PA: proanthocyanidin index, $\mathrm{OH}$ : ethanol content (\%vol.), $\mathrm{pH}$ : wine $\mathrm{pH}$ value, $\mathrm{SO}_{2}$ : free $\mathrm{SO}_{2}$ content, $\mathrm{AA}$ : ascorbic acid concentration, $\mathrm{CF}$ : ciscaffeoyl tartaric acid concentration, TE: trans-caffeoyl tartaric acid concentration, CC: $c i s-p$-coumaroyl tartaric acid concentration, TC: trans-p-coumaroyl tartaric acid concentration, TL: trans-feruloyl tartaric acid concentrations, MY: myricetin concentration, Q1: quercetin glucoside concentration, and Q2: quercetin glucuronide concentration.

wines, regardless of the different winemaking techniques used to produce them.

To further describe the differences among the abovementioned groups, the variables that constitute PC2 also have to be considered. PC2 describes a residual percentage of variance of about 15\% (Figure 4) and it is mainly characterized by alcohol and $\mathrm{pH}$, located at negative weights, and by free $\mathrm{SO}_{2}$ and total anthocyanin index located at a positive weight.

In Figure 3, it is possible to see that PC2 separates the groups of Refosco, Nero d'Avola, Albarossa, and Cornarea samples (located at the top of the figure) from the group of Primitivo and Uvalino (located at the bottom).

The role of alcohol content and $\mathrm{pH}$ value on the DPPHEPR assay was investigated in more detail. A sample of a wine characterized by very low alcohol content $(9.5 \% \mathrm{v} / \mathrm{v}$ ethanol) was tested for DPPH scavenging activity and then its alcohol content was increased up to $12.00 \%$ and $14.50 \% \mathrm{v} / \mathrm{v}$ by adding absolute ethanol. No differences were observed on the DPPH scavenging activity before and after such ethanol additions. The effect of $\mathrm{pH}$ was evaluated by varying the $\mathrm{pH}$ of a natural wine from 2.98 to 3.98 through the addition of hydrochloric acid or sodium hydroxide, respectively. No variations in DPPH scavenging ability were observed. These experiments ruled out any direct effect of these parameters. The correlation observed on PC2 between ethanol content and the $\mathrm{pH}$ value can be explained considering that a high alcohol content in the wine samples derives from the use of grapes with a high sugar content (such as very mature grapes); this leads to a final product with a relatively high $\mathrm{pH}$ (low acidity). Indeed, Primitivo and Uvalino are both wines with a high alcohol content and low acidity, since they were made with very ripe grapes.

Despite the low amounts of $\mathrm{SO}_{2}$ found in all the samples, this variable allows PC2 to highlight differences among the biological samples Primitivo and Uvalino with respect to Refosco, Nero d'Avola, Albarossa, and Cornarea that stem from microwinemaking processes. In the latter winemaking procedure, slightly more $\mathrm{SO}_{2}$ is required to prevent oxidation, because of the small volume of grapes used.

\section{Conclusions}

In this work, 36 wine samples were fully characterised by chromatographic and spectrophotometric techniques, and their antioxidant activities were evaluated by DPPH-EPR assay. The EPR measure is quite fast and does not require any sample pretreatment.

The resulting dataset was subjected to multivariate PCA analysis. The loading plot shows that the most important variables contributing to the wines' antioxidant power are total flavonoid, total phenol, and proanthocyanidin indices together with fertaric acid, trans-caftaric acid, trans-coutaric acid, and both quercetin glucoside and quercetin glucuronide. From the score plot, it is possible to observe that $\mathrm{PCl}$ can distinguish the seven different cultivars on the basis of their antioxidant capacity so that the meaning of "antioxidant power" can be assigned to the macrovariable PC1. On the other hand, PC2 is able to point out some differences among the samples arising from variations in $\mathrm{pH}$, alcohol, and free $\mathrm{SO}_{2}$. The observed differences among samples could not be evidenced with the classical univariate approach.

\section{Additional Points}

The authors studied 36 wines produced with grapes from different cultivars and areas of Italy. Red wines were assessed using spectrophotometric and HPLC determinations. Antioxidant power of red wine was tested with DPPH assays.

\section{Competing Interests}

The authors declare that there are no competing interests regarding the publication of this paper.

\section{Acknowledgments}

The authors are grateful to the Regione Piemonte (Torino) (Marcandis Project) and to CRA (Alessandria) and CRT (Torino) Foundations for their financial support.

\section{References}

[1] S. McGuire and US Department of Agriculture and US Department of Health and Human Services, "Dietary Guidelines for Americans, 2010. Washington, DC: US Government Printing Office, January 2011," Advances in Nutrition, vol. 2, no. 3, pp. 293-294, 2011. 
[2] E. N. Frankel, A. L. Waterhouse, and P. L. Teissedre, "Principal phenolic phytochemicals in selected California wines and their antioxidant activity in inhibiting oxidation of human lowdensity lipoproteins," Journal of Agricultural and Food Chemistry, vol. 43, no. 4, pp. 890-894, 1995.

[3] M. Grønbæk, "The positive and negative health effects of alcohol- and the public health implications," Journal of Internal Medicine, vol. 265, no. 4, pp. 407-420, 2009.

[4] H. Theobald, L. O. Bygen, J. Carstensen, and P. Engfeldt, "A moderate intake of wine is associated with reduced total mortality and reduced mortality from cardiovascular disease," Journal of Studies on Alcohol, vol. 61, no. 5, pp. 652-656, 2000.

[5] V. Habauzit and C. Morand, "Evidence for a protective effect of polyphenols-containing foods on cardiovascular health: an update for clinicians," Therapeutic Advances in Chronic Disease, vol. 3, no. 2, pp. 87-106, 2012.

[6] J. Lachman, M. Šulc, and M. Schilla, "Comparison of the total antioxidant status of Bohemian wines during the wine-making process," Food Chemistry, vol. 103, no. 3, pp. 802-807, 2007.

[7] M. Naczk and F. Shahidi, "Nutritional implications of canola condensed tannins," in Antinutrients and Phytochemicals in Food, F. Shahidi, Ed., vol. 662 of ACS Symposium Series, pp. 186208, 1997.

[8] A. Coletta, S. Berto, P. Crupi et al., "Effect of viticulture practices on concentration of polyphenolic compounds and total antioxidant capacity of Southern Italy red wines," Food Chemistry, vol. 152, pp. 467-474, 2014.

[9] C. Barril, A. C. Clark, and G. R. Scollary, "Chemistry of ascorbic acid and sulfur dioxide as an antioxidant system relevant to white wine," Analytica Chimica Acta, vol. 732, pp. 186-193, 2012.

[10] C. Coetzee, K. Lisjak, L. Nicolau, P. Kilmartin, and W. J. du Toit, "Oxygen and sulfur dioxide additions to Sauvignon blanc must: effect on must and wine composition," Flavour and Fragrance Journal, vol. 28, no. 3, pp. 155-167, 2013.

[11] I. Garaguso and M. Nardini, "Polyphenols content, phenolics profile and antioxidant activity of organic red wines produced without sulfur dioxide/sulfites addition in comparison to conventional red wines," Food Chemistry, vol. 179, pp. 336-342, 2015.

[12] P.-C. Hugo, J. Gil-Chávez, R. R. Sotelo-Mundo, J. Namiesnik, S. Gorinstein, and G. A. González-Aguilar, "Antioxidant interactions between major phenolic compounds found in 'Ataulfo' mango pulp: chlorogenic, gallic, protocatechuic and vanillic acids," Molecules, vol. 17, no. 11, pp. 12657-12664, 2012.

[13] A. Garofolo, B. Giannini, S. Favale, and M. Savino, "Free radical scavenging activity (DPPH) of red grapes and wines of Vitis vinifera (L.) cv. Cesanese d'Affile clones," Rivista di Viticoltura e di Enologia, vol. 62, no. 2-3, pp. 11-27, 2009.

[14] M. De Nisco, M. Manfra, A. Bolognese et al., "Nutraceutical properties and polyphenolic profile of berry skin and wine of Vitis vinifera L. (cv. Aglianico)," Food Chemistry, vol. 140, no. 4, pp. 623-629, 2013.

[15] L. Stavikova, M. Polovka, B. Hohnová, P. Karásek, and M. Roth, "Antioxidant activity of grape skin aqueous extracts from pressurized hot water extraction combined with electron paramagnetic resonance spectroscopy," Talanta, vol. 85, no. 4, pp. 2233-2240, 2011.

[16] N. Paixão, R. Perestrelo, J. C. Marques, and J. S. Câmara, "Relationship between antioxidant capacity and total phenolic content of red, rosé and white wines," Food Chemistry, vol. 105, no. 1, pp. 204-214, 2007.
[17] K. F. Pirker, J. Oliveira, V. De Freitas, B. A. Goodman, and N. Mateus, "Antiradical properties of red wine portisins," Journal of Agricultural and Food Chemistry, vol. 59, no. 21, pp. 1183311837, 2011.

[18] A. Staško, V. Brezová, M. Mazúr, M. Čertík, M. Kaliňák, and G. Gescheidt, "A comparative study on the antioxidant properties of Slovakian and Austrian wines," LWT-Food Science and Technology, vol. 41, no. 10, pp. 2126-2135, 2008.

[19] F. Cimino, V. Sulfaro, D. Trombetta, A. Saija, and A. Tomaino, "Radical-scavenging capacity of several Italian red wines," Food Chemistry, vol. 103, no. 1, pp. 75-81, 2007.

[20] V. Fogliano, V. Verde, G. Randazzo, and A. Ritieni, "Method for measuring antioxidant activity and its application to monitoring the antioxidant capacity of wines," Journal of Agricultural and Food Chemistry, vol. 47, no. 3, pp. 1035-1040, 1999.

[21] J. Lee and C. Rennaker, "Antioxidant capacity and stilbene contents of wines produced in the Snake River Valley of Idaho," Food Chemistry, vol. 105, no. 1, pp. 195-203, 2007.

[22] H. Li, X. Wang, Y. Li, P. Li, and H. Wang, "Polyphenolic compounds and antioxidant properties of selected China wines," Food Chemistry, vol. 112, no. 2, pp. 454-460, 2009.

[23] S. M. Azcarate, M. A. Cantarelli, E. J. Marchevsky, and J. M. Camiña, "Evaluation of geographic origin of Torrontés wines by chemometrics," Journal of Food Research, vol. 2, no. 5, pp. 48-56, 2013.

[24] S. Kallithraka, A. Mamalos, and D. P. Makris, "Differentiation of young red wines based on chemometrics of minor polyphenols constituents," Journal of Agricultural and Food Chemistry, vol. 55, no. 9, pp. 3233-3239, 2007.

[25] H.-F. Liu, B.-H. Wu, P.-G. Fan, S.-H. Li, and L.-S. Li, "Sugar and acid concentrations in 98 grape cultivars analyzed by principal component analysis," Journal of the Science of Food and Agriculture, vol. 86, no. 10, pp. 1526-1536, 2006.

[26] S. Kallithraka, D. Kim, A. Tsakiris, I. Paraskevopoulos, and G. Soleas, "Sensory assessment and chemical measurement of astringency of Greek wines: correlations with analytical polyphenolic composition," Food Chemistry, vol. 126, no. 4, pp. 1953-1958, 2011.

[27] V. Roginsky and E. A. Lissi, "Review of methods to determine chain-breaking antioxidant activity in food," Food Chemistry, vol. 92, no. 2, pp. 235-254, 2005.

[28] M. Kopáni, P. Celec, L. Danišovič, P. Michalka, and C. Biró, "Oxidative stress and electron spin resonance," Clinica Chimica Acta, vol. 364, no. 1-2, pp. 61-66, 2006.

[29] J. Lachman, M. Šulc, K. Faitová, and V. Pivec, "Major factors influencing antioxidant contents and antioxidant activity in grapes and wines," International Journal of Wine Research, vol. 1, no. 1, pp. 101-121, 2009.

[30] R. Di Stefano, M. C. Cravero, and N. Gentilini, "Methods for the study of wine polyphenols," L'Enotecnico, vol. 25, no. 5, pp. 83-89, 1989.

[31] R. Di Stefano and M. C. Cravero, "The grape phenolics determination," Rivista di Viticoltura e di Enologia, vol. 2, pp. 37-45, 1991.

[32] D. Kammerer, A. Claus, R. Carle, and A. Schieber, "Polyphenol screening of pomace from red and white grape varieties (Vitis vinifera L.) by HPLC-DAD-MS/MS," Journal of Agricultural and Food Chemistry, vol. 52, no. 14, pp. 4360-4367, 2004.

[33] D. L. Massart, B. G. M. Vandeginste, S. N. Deming, Y. Michotte, and L. Kaufman, Chemometrics: A Textbook, Elsevier, Amsterdam, Netherlands, 1988. 
[34] V. Cheynier, M. Dueñas-Paton, E. Salas et al., "Structure and properties of wine pigments and tannins," American Journal of Enology and Viticulture, vol. 57, no. 3, pp. 298-305, 2006.

[35] H. Fulcrand, M. Dueñas, E. Salas, and V. Cheynier, "Phenolic reactions during winemaking and aging," American Journal of Enology and Viticulture, vol. 57, no. 3, pp. 289-297, 2006.

[36] V. L. Singleton, J. Zaya, E. Trousdale, and M. Salgues, "Caftaric acid in grapes and conversion to a reaction product during processing," Vitis, vol. 23, no. 2, pp. 113-120, 1984. 

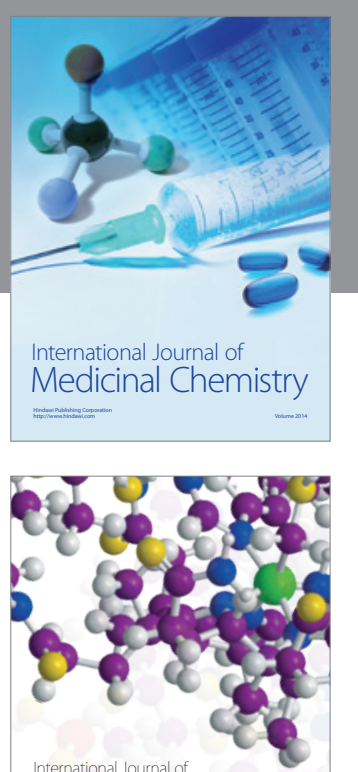

Carbohydrate Chemistry

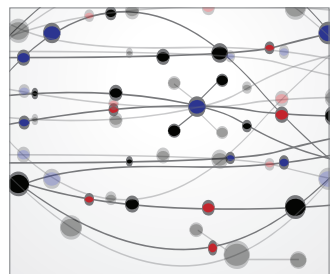

The Scientific World Journal
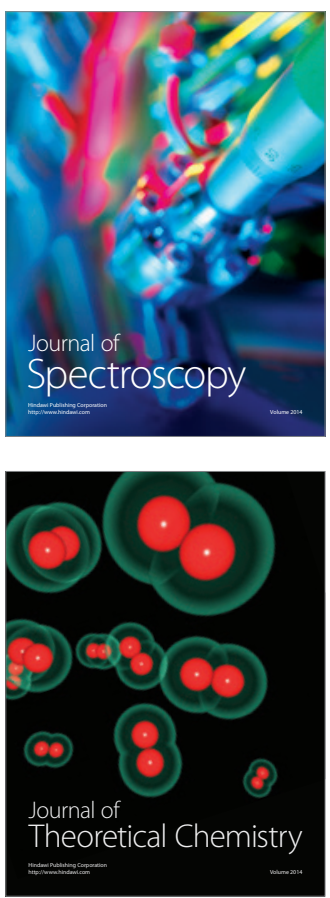
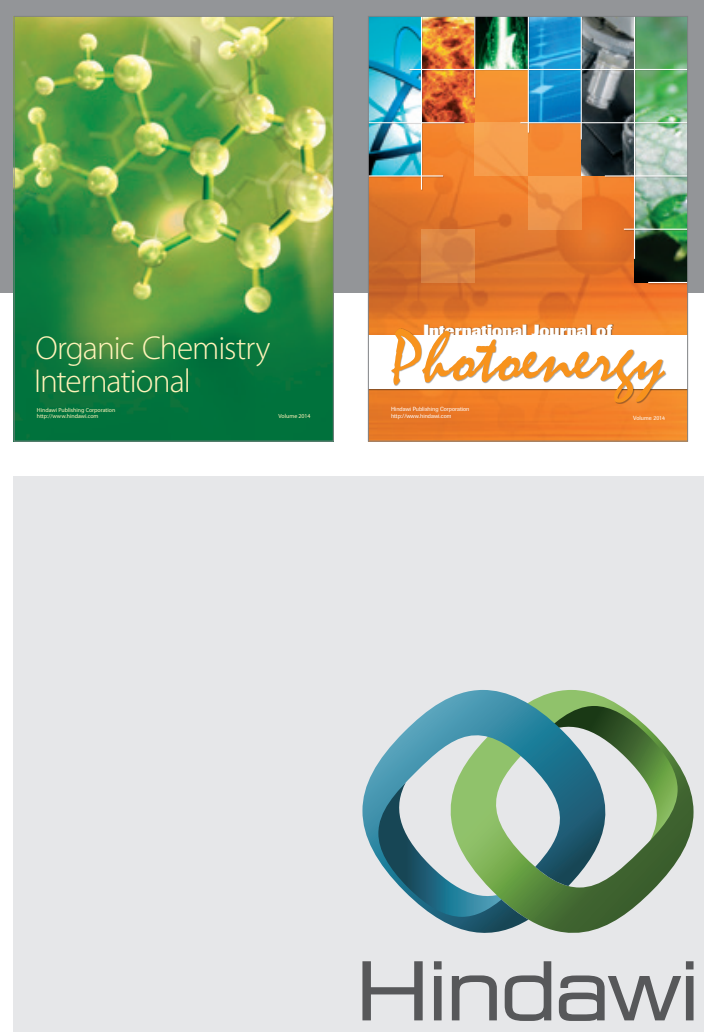

Submit your manuscripts at

http://www.hindawi.com

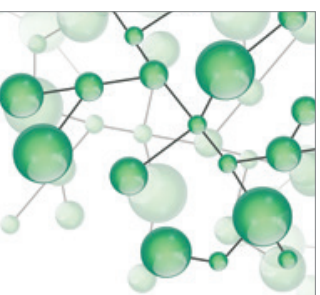

International Journal of

Inorganic Chemistry

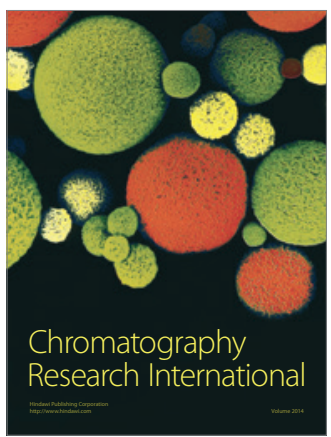

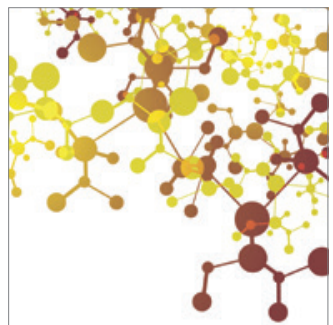

Applied Chemistry
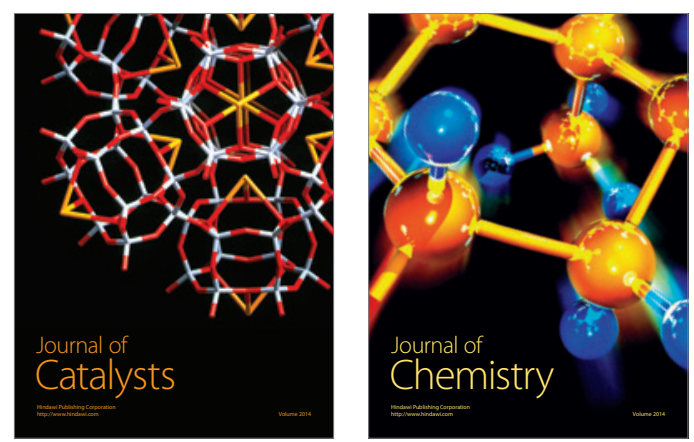
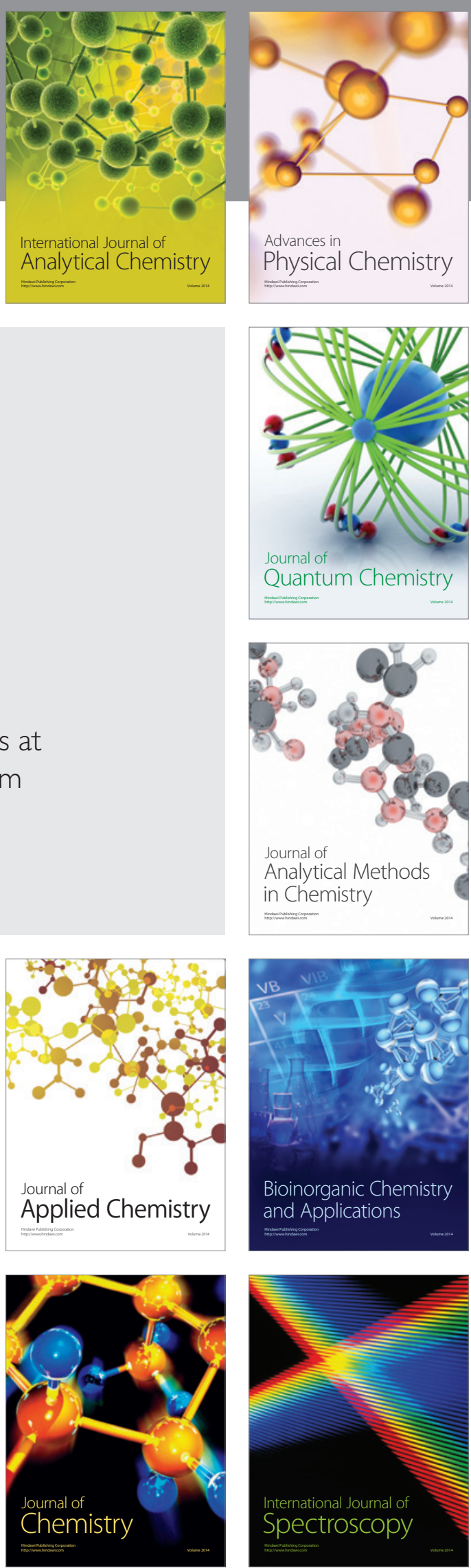